\title{
Review
}

Mahmood S. Jameel*, Azlan Abdul Aziz*, and Mohammed Ali Dheyab

\section{Green synthesis: Proposed mechanism and factors influencing the synthesis of platinum nanoparticles}

https://doi.org/10.1515/gps-2020-0041

received April 09, 2020; accepted June 11, 2020

\begin{abstract}
Platinum nanoparticles (Pt NPs) have attracted interest in catalysis and biomedical applications due to their unique structural, optical, and catalytic properties. However, the conventional synthesis of Pt NPs using the chemical and physical methods is constrained by the use of harmful and costly chemicals, intricate preparation requirement, and high energy utilization. Hence, this review emphasizes on the green synthesis of Pt NPs using plant extracts as an alternative approach due to its simplicity, convenience, inexpensiveness, easy scalability, low energy requirement, environmental friendliness, and minimum usage of hazardous materials and maximized efficiency of the synthesis process. The underlying complex processes that cover the green synthesis (biosynthesis) of Pt NPs were reviewed. This review affirms the effects of different critical parameters $(\mathrm{pH}$, reaction temperature, reaction time, and biomass dosage) on the size and shape of the synthesized Pt NPs. For instance, the
\end{abstract}

\footnotetext{
* Corresponding author: Mahmood S. Jameel, Nano-Biotechnology Research and Innovation (NanoBRI), Institute for Research in Molecular Medicine (INFORMM), Universiti Sains Malaysia, 11800, Pulau Pinang, Malaysia; Nano-Optoelectronics Research and Technology Lab (NORLab), School of Physics, Universiti Sains Malaysia, 11800, Pulau Pinang, Malaysia,

e-mail: mahmood@student.usm.my

* Corresponding author: Azlan Abdul Aziz, Nano-Biotechnology Research and Innovation (NanoBRI), Institute for Research in Molecular Medicine (INFORMM), Universiti Sains Malaysia, 11800, Pulau Pinang, Malaysia; Nano-Optoelectronics Research and Technology Lab (NORLab), School of Physics, Universiti Sains Malaysia, 11800, Pulau Pinang, Malaysia,

e-mail: lan@usm.my, tel: +60-4-653-3814

Mohammed Ali Dheyab: Nano-Biotechnology Research and Innovation (NanoBRI), Institute for Research in Molecular Medicine (INFORMM), Universiti Sains Malaysia, 11800, Pulau Pinang, Malaysia; Nano-Optoelectronics Research and Technology Lab (NORLab), School of Physics, Universiti Sains Malaysia, 11800, Pulau Pinang, Malaysia
}

average particle size of Pt NPs was reported to decrease with increasing $\mathrm{pH}$, reaction temperature, and concentration of plant extract.

Keywords: Pt NPs, green synthesis, plant extract, reaction mechanism

\section{Introduction}

In current times, inorganic nanoparticles (NPs) have garnered immense research interest in the field of science and technology [1,2]. Platinum nanoparticles (Pt NPs) are particularly exploited for catalysis and biomedical applications because of their unique crystalline, optical, and catalytic properties, which allow them to play the integrated role of nanoenzymes, nanocarriers, and nanodiagnostic tool [3,4]. Physical and chemical methods were prevalent during the early phases of synthesizing Pt NPs [5-8]. The physicochemical methods guarantee flexibility in modifying the crystal structure of the NPs to achieve the required morphology and size $[9,10]$. Nonetheless, the utilization of toxic substances and harsh synthesis conditions ultimately lead to health and environmental issues. Therefore, there is a need for "green chemistry" to synthesize eco-friendly materials [11]. Hence, plantmediated synthesis has been incorporated into the preparation of Pt NPs. Living plants, plant extracts, and plant biomass are basic but efficacious precursor materials for the extracellular biosynthesis of metal NPs [12]. Moreover, the bioactive molecules (such as amino acids, phenols, aldehydes, ketones, carboxylic acid, and nitrogenous compounds) activate the bioreduction of metal nanoparticles, thus reducing, capping, or stabilizing the synthesis process [13]. However, studies on the biosynthesis of Pt NPs are somewhat limited. Till date, no study has investigated the bioreductive mechanism involved in the plant-mediated synthesis of Pt NPs as well as factors that affect the synthesis. Hence, this paper provides a detailed review on the methods of synthesizing Pt NPs, 
proposed reaction mechanism of reduction, and stabilizes Pt NPs, in addition to the parameters (e.g., $\mathrm{pH}$, reaction temperature, reaction time, and biomass dosage) that influence the biosynthesis of Pt NPs.

\section{Synthesis of Pt NPs}

The size, morphology, composition, and structure of $\mathrm{Pt}$ NPs as well as the presence of a capping agent control their application for industrial and biomedical purposes [3,9,14-17]. This has required the development of novel synthesis methods for the optimization of these intrinsic properties. The modification and functionalization of $\mathrm{Pt}$ NPs for biomedical uses are directed by recently obtained data, which revealed that the physicochemical properties, dispersivity, and stability of the NPs in a biological environment play key roles in determining their safety or toxic levels. The critical challenges encumbering the potential use of Pt NPs as drug carriers and antioxidant materials include biocompatibility, specifically defined properties, and contamination-free production (e.g., endotoxin, Pt precursors, toxic unreacted reagents, organic solvents, etc.) [18]. The several synthesis techniques are discussed in the underlying subsections.

\subsection{Chemical methods}

The chemical synthesis methods, including wet chemical reduction (WCR) [19], electrochemical reduction [20,21], galvanic displacement [22,23], and chemical vapor deposition $[24,25]$, are all employed to precisely define the physicochemical properties of NPs. Mainly, WCR is frequently utilized because of its ability to successfully control the features of NPs. WCR synthesizes Pt NPs from Pt precursor solutions with the aid of a reducing agent [19], which enables the stringent control of features of NPs such as size and morphology by altering the precursor concentration [19], reaction temperature [9], and incorporation of organic or inorganic ligands [26-29]. The use of WCR methods to synthesize Pt NPs with enhanced catalytic performances has been extensively explored. A number of shapes modifying agents (polymers, surfactants, and capping agents) have also been used to facilitate the asymmetric synthesis of NPs. Multiphase synthesis setups have also been developed [30-32], which include utilizing gaseous reducing agents to attain enhanced control of reaction parameters [33].
However, this approach is constrained by the need for vast quantities of organic solvents, surfactants, and capping agents that could increase the toxicity levels of NPs. Besides, a huge volume of production (large-scale) can create an environmental threat. Hence, the use of microwave heating and glycerol, as a reducing agent and solvent, has been developed to allow for industrial upscaling and reduced environmental impact [34,35]. Thiol chemistry is also frequently used to synthesize NPs that are stable in an aqueous environment or inorganic media. Thiol ligands, such as alkane thiols [36-38] or thiols bearing polar groups $[29,39,40]$, have been used to synthesize stable Pt clusters with controlled size and precise morphology. These techniques enable the further decrease in the size of NPs, thereby elevating the surface/volume ratio. Despite the issue of decreased catalytic performance with the addition of thiols, their presence on the surface can transform the properties of the NPs such as the combination of hydrophobic and hydrophilic ligands on the same NP to support selective contact with substrates and the environment [41].

Conversely, these chemicals (aromatic, aliphatic, and amino-terminated thiols) exhibit potential hazardous effects and can be lethal both in vitro and in vivo [42]. To synthesize Pt NPs that are biocompatible, the approach of using "green reagents" like sodium citrate and ascorbic acid is most promising, due to the fact they allow robust control on solvent and guarantee the purity of reagents [42-45]. This synthesis approach can also assure precise control on size, morphology, and catalytic properties, in addition to reasonably high yield [42]. For example, citrate-capped Pt NPs are reported to display excellent cytocompatibility and high antioxidant capability [43]. Furthermore, the use of green reagents enables simple surface functionalization of NPs, which is essential to the synthesis of Pt NPs for biomedical purposes, since the biological characteristics of nanomaterials are highly dependent on their bare surface area. Therefore, since the surface coating of NPs affects their toxic levels and specific targeting, biogenic synthesis techniques using biomolecules as templates have been initiated [46]. For instance, apoferritin protein encapsulated Pt NPs were proven to enhance the cellular uptake and considerably decrease membrane damage [47-49]. Similarly, Wang et al. [50] developed dendrimers encapsulated Pt NPs to replicate the catalytic centers within natural enzymes. Yamamoto et al. [51] posited that the catalytic activity of Pt clusters was significantly improved when encapsulated with dendrimers, enabling the controlled growth of the nanomaterial. The utilization of dendrimers as encapsulating 
agents for the synthesis of Pt NPs and clusters has also been explored in other studies [51,52].

\subsection{Physical methods}

Other synthesis methods that have recently gained attention include laser ablation [53,54], aerosol-assisted deposition [55], electron-beam-induced reduction [56], and flame synthesis [57,58]. These physical methods were developed as efforts to deal with certain constraints of the chemical methods (such as toxic reagents, organic solvents). The laser ablation technique utilizes the continuous or pulsed application of a high-power laser beam for the evaporation of NPs from a solid source. This versatile technique is anchored in the control of pulses, reaction temperature, and atmospheric gas pressure to attain a particular set of NP properties. The key benefit of using this approach is the absence of redundant coatings, solvent contaminations, and stabilizers, which are problems usually associated with synthesis in nanomedicine [59]. However, the mechanism of NP production has not been entirely elucidated. Moreover, the high required dilution in addition to complexities of modifying the size, morphology, and production yield of NPs has constrained their use $[42,60,61]$. Furthermore, the stability of these NPs in aqueous solutions is a complex procedure. Nonetheless, laser ablation is capable of synthesizing stable NPs in the absence of stabilizers, which is attributable to inherent electrical repulsion effects derived from the presence of surface charges on the NPs [62,63]. Nevertheless, this could pose a problem in biological systems, since clustering/agglomeration and precipitation might simultaneously arise during the incubation of NPs under intricate conditions, such as cell culture media and solutions with high ionic strength. Cathodic corrosion is one more basic physical technique of synthesizing Pt NPs, which entails the conversion of a bulk alloy electrode in a suspension of NPs with similar constituents [64]. However, this approach is similarly constrained by relatively low production yield and size modification.

\subsection{Green synthesis}

Bio-assisted synthesis techniques were developed as viable substitutes of chemical and physical techniques. Their advantages include the absence of unwanted reaction solvents. The application of biological syntheses has focused on the production of noble metal nanomaterials, because of their ease of reduction using weak reducing agents [65-73]. Few studies have explained the production of Pt NPs by means of the green synthesis approach [74-77]. Nonetheless, procedures have been successfully developed to synthesize monodisperse and stable Pt NPs via the biosynthesis approach, using bacteria [78-81], cyanobacteria [82,83], seaweeds [84,85], fungi [86-88], plants [89-91], in addition to bio-derived products which include honey $[92,93]$. Some studies exploited the activity of specific hydrogenase enzymes in sulfate-reducing bacteria to reduce Pt(Iv) into Pt NPs [94,95]. Like the WCR, the concentrations of Pt salt and protein serve key roles in tuning the morphology and dimension of the NPs during biogenic synthesis [96]. The synthesis of Pt NPs using fungi, such as Neurospora crassa [88] and Fusarium oxysporum $[86,87,97]$, is a valuable "scale-up" approach. The phytochemical constituents of plant extracts [12] and wood $[98,99]$ have also been exploited as capping agents in the biogenic synthesis of metal NPs. The biosynthesis of Pt NPs via phytoreduction was first reported in 2009, where 2-12 nm-sized Pt NPs were synthesized using leaf extracts with $90 \%$ yield and extremely low leaf biomass [100]. Presently, studies have reported the use of a wide and diverse range of vegetable-derived products such as Diospyros kaki [101], Ocimum sanctum [102], Medicago sativa, and Brassica juncea [103] to synthesize Pt NPs. Using the root extract of Asparagus racemosus Linn, Raut et al. [104] developed a quick procedure of synthesizing monodisperse, spherical Pt NPs with a size range of 1-6 $\mathrm{nm}$ in aqueous solution under ambient conditions.

The key benefits of synthesizing Pt NPs from plant extracts are simplicity, convenience, inexpensiveness, easy scalability, low energy requirement, environmental friendliness, and minimum use of hazardous substances and maximized effectiveness of the synthesis process. It is particularly pertinent that the synthesis process of NPs is devoid of toxic materials. The plant extract-based synthesis increases the stability of NPs in terms of size and shape, and produces higher yield compared to other physical and chemical methods.

\section{Proposed reaction mechanism}

Ever since ancient times, plants are principally investigated for their curative value against different diseases and infections [105-107]. As well, plants display huge 
Table 1: Studies of the influence of various plant on size, shape, and stabilization of Pt NPs

\begin{tabular}{|c|c|c|c|c|c|c|c|}
\hline \multirow[t]{2}{*}{ No. } & \multirow[t]{2}{*}{ Plant } & \multicolumn{2}{|c|}{ The possible biomolecules responsible for } & \multirow{2}{*}{$\begin{array}{l}\text { (TEM) } \\
\text { Size nm }\end{array}$} & \multirow[t]{2}{*}{ Shape } & \multirow[t]{2}{*}{ Zeta mV } & \multirow[t]{2}{*}{ Ref. } \\
\hline & & Reduction & Stabilization & & & & \\
\hline 1 & Ocimum sanctum & $\begin{array}{l}\text { Terpenoids/reducing } \\
\text { sugars }\end{array}$ & Terpenoids & 23 & Irregular shape & - & 102 \\
\hline 2 & Azadirachta indica & Terpenoids/sugars & Terpenoids & $5-50$ & Sphere & - & 119 \\
\hline 3 & Cacumen platycladi & Sugars/flavonoids & - & $2.4 \pm 0.8$ & Sphere & - & 12 \\
\hline 4 & Coffea arabica seed & Protocathechuic acid & $\begin{array}{l}\text { Hydroxyl groups of } \\
\text { polyphenolic } \\
\text { compounds }\end{array}$ & $180-500$ & $\begin{array}{l}\text { Square and } \\
\text { rectangular- } \\
\text { shaped }\end{array}$ & - & 125 \\
\hline 5 & Gum olibanum & Chloroplatinic acid & Gum proteins & 4.4 & Spherical & -12.7 & 126 \\
\hline 6 & Maytenusroyleanus & Phenol compounds & Phytochemicals & 5 & Spherical & -41 & 120 \\
\hline 7 & Garcinia mangostana L. & Amines/polyols & Amines/polyols & $20-25$ & Spherical & -13 & 124 \\
\hline 8 & Sechiumedule & Ascorbic acid & Ascorbic acid & $10-70$ & Spherical & -20 & 127 \\
\hline 9 & Black cumin seed & $\begin{array}{l}\text { Hydroxyl and methyl } \\
\text { groups }\end{array}$ & $\begin{array}{l}\text { Hydroxyl and methyl } \\
\text { groups }\end{array}$ & 3.47 & Spherical & - & 128 \\
\hline 10 & Water hyacinth plant & $\begin{array}{l}\text { Hydroxyl, nitrogen and } \\
\text { carbohydrate groups }\end{array}$ & $\begin{array}{l}\text { Hydroxyl, nitrogen and } \\
\text { carbohydrate groups }\end{array}$ & 3.74 & Spherical & -0.0536 & 92 \\
\hline 11 & $\begin{array}{l}\text { Xanthium } \\
\text { strumarium leaf }\end{array}$ & Limonene/borneol & Limonene/borneol & 20 & Rectangular & - & 129 \\
\hline
\end{tabular}

potential in detoxifying heavy metals in the course of treatment [108]. Also, some plants possess firm and highly resistant biological systems as well as physiology that allows them to withstand acute metal concentrations. This intrinsic property made researchers utilize plants in the field of nanotechnology $[109,110]$. In addition, aside from simplicity and cost-effectiveness, the use of plant entails decent reaction conditions that are nonhostile to the environment. Presently, biosynthesis of inorganic nanoparticles, for instance, Pt NPs using plants and their derivatives is under enormous investigation. The bioreduction of metal nanoparticles is attributable to the existence of diverse bioactive molecules that include amino acids, aldehydes, phenols, carboxylic acid, ketones, and nitrogen-bearing compounds, which serve to reduce, cap/functionalize, or stabilize the NPs in the course of synthesis [13]. For instance, Sheny et al. [111] employed tea polyphenol in the synthesis of Pt NPs. The phenolic compounds present in tea polyphenols serve as both reducing and capping agents by forming complexes with the Pt ions, reducing them to nanoparticles of diverse sizes and morphologies [112-114].

Nonetheless, the studies on the biosynthesis of Pt NPs are quite limited. Hence, researchers are constantly probing novel ways of rapidly synthesizing Pt NPs using the different plant components which include flower, root, leaf, fruit, bark, or by-products like gum [92,115-118]. Similar to other inorganic NPs, the synthesis of Pt NPs is supported by bioactive molecules that are present in the plants. Thus, the reduction and stabilization mechanisms of biosynthesized Pt NPs need to be fully elucidated. Fourier transform infrared spectroscopy (FTIR) is a valuable tool for analyzing the bimolecular composition prior and post-reaction. FTIR mechanism can determine the bioactive molecules responsible for reducing and stabilizing the Pt NPs. Generally, FTIR peaks denote the different vibrations of functional groups present in a sample. Comparative analysis shows that some characteristic FTIR peaks of the plant extract disappear or become less intense or are shifted when observed in the FTIR spectrum of Pt NPs synthesized by plant extract, which could be indicative of the reduction process, while the FTIR peaks that remain unchanged are suggestive of the functional groups responsible for stabilizing the NPs.

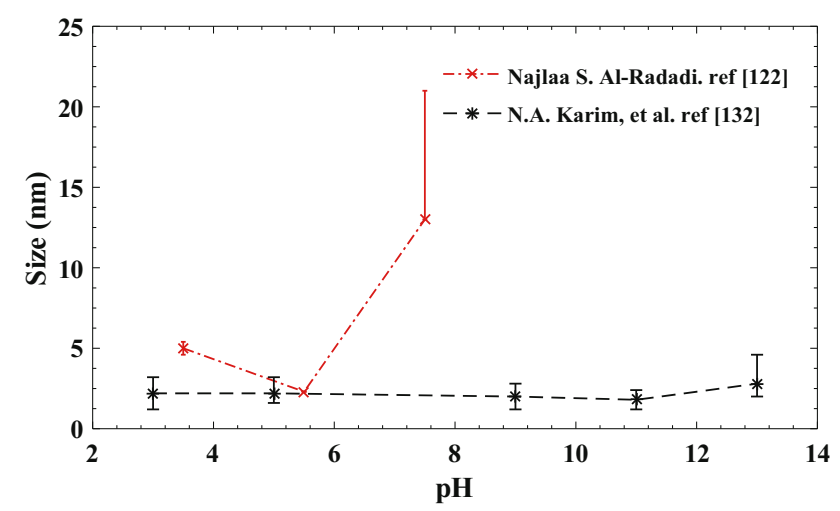

Figure 1: The effect of $\mathrm{pH}$ on the size variation, adapted from refs. [122 and 132]. 
For example, Thirumurugan et al. [119] identified distinct FTIR peaks at 1728.22, 1365.60, and $1219.01 \mathrm{~cm}^{-1}$ for Pt NPs biosynthesized from Azadirachta indica extract, corresponding to carbonyls, alkanes, and aliphatic amines, respectively. It was inferred that Azadirachta indica leaf broth contains terpenoid which is capable of reducing and stabilizing the nanoparticles [101].

Ullah et al. [120] reported that the phytochemicals existing in the aqueous leaf extract of Maytenusroyleanus reduce Pt ions into Pt NPs and cap them. The FTIR analysis of Maytenusroyleanus mediated Pt NPs reveals a decline in the peak intensities, signifying a possible reaction of phytochemicals with inorganic compounds in the synthesis and stabilization of Pt NPs. A significant shift in the stretching $\mathrm{O}-\mathrm{H}$ vibration of phenol compounds from 3,310 to $3,412 \mathrm{~cm}^{-1}$ was observed, while the stretching vibrations of $\mathrm{C}=\mathrm{O}$ and $\mathrm{N}-\mathrm{H}$ in amide II shifted from 1,608 to $1,615 \mathrm{~cm}^{-1}$ and 2,938 to $2,925 \mathrm{~cm}^{-1}$, respectively, which clearly demonstrates that Pt NPs can be stabilized by diverse phytochemicals existing in the aqueous Maytenusroyleanus extract.

The phytochemical components of black cumin seeds (Nigella sativa L.) include alkaloids (nigellimin, nigellimin$\mathrm{N}$-oxide, nigellidin, and nigellicin), terpenoids (carvone, limonene, citronellol, carvacrol, 4-terpineol), saponins, tannins, and derivatives. These phytochemicals, comprising functional groups, e.g., hydroxyl and methyl groups, can serve as both reducing and capping agents in the biosynthesis of Pt NPs [121].

FTIR spectra of Ajwa (dried) and Pt NPs (capped) confirm the presence of diverse kinds of polyphenols in the biosynthesized Pt NPs. The bioreduction and capping of Pt NPs synthesized from water-soluble polyphenols is indicted by the loss of the distinct peak at $1,760 \mathrm{~cm}^{-1}$ in

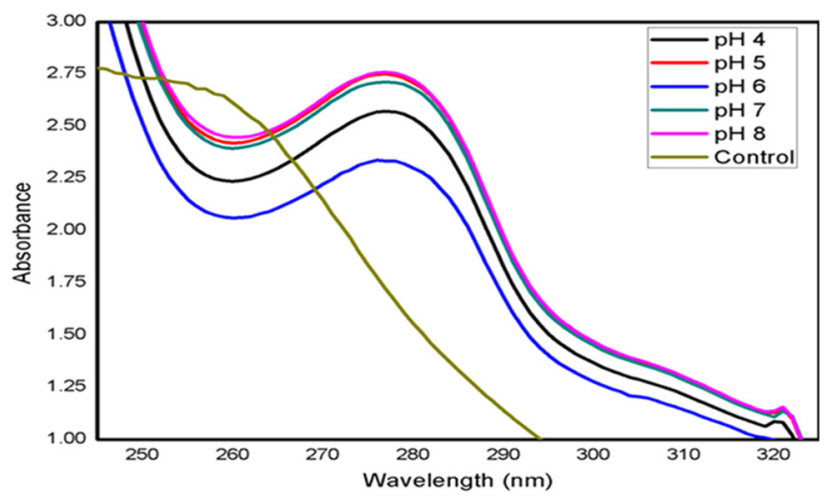

Figure 2: The optical spectra presents the effect of $\mathrm{pH}$ on the green synthesis of Pt NPs (reprinted from ref. [124], copyright 2020, with permission from Elsevier).

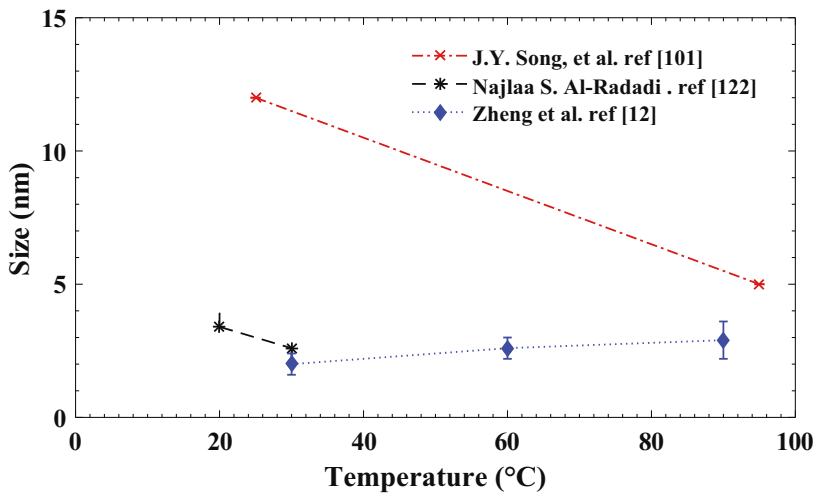

Figure 3: The effect of reaction temperature on the particle size variation of Pt NPs, adapted from refs. [101, 122, and 12].

Pt NPs [122]. Ganaie et al. [123] reported that the polysaccharides and proteins in the Antigononleptopus plant extract account for the reduction of Pt ions to Pt NPs as well as the stabilization of Pt NPs, while Nishanthi et al. [124] assigned the bands around $1,430-1,440 \mathrm{~cm}^{-1}$ and $1,275-1,285 \mathrm{~cm}^{-1}$ in the FTIR spectrum of Pt NPs to the secondary aromatic amines and polyols such as hydroxyl flavones and hydroxyl of xanthones. The amines and polyols contained in Garcinia mangostana rind extract were also shown to reduce and stabilize Pt NPs. The biosynthesis of Pt NPs using different plant extract and their respective biomolecules for reduction and stabilization are summarized in Table 1.

\section{Factors influencing biosynthesis of Pt NPs}

There are several variables that control the synthesis, characteristics, and use of nanoparticles in the course of plant-mediated biosynthesis. These factors are discussed in the underlying subsections.

\subsection{Solution $\mathrm{pH}$}

The $\mathrm{pH}$ of the solution serves a vital function in plantmediated biosynthesis of nanoparticles by influencing the size, morphology, and rate of synthesis [130]. This influence is attributed to an increase in the development of nucleation centers as $\mathrm{pH}$ increases. The reduction of metal ions to metal nanoparticles increases concomitantly with the expansion of the nucleation center (the effect of protonation-deprotonation of active ingredients could be 

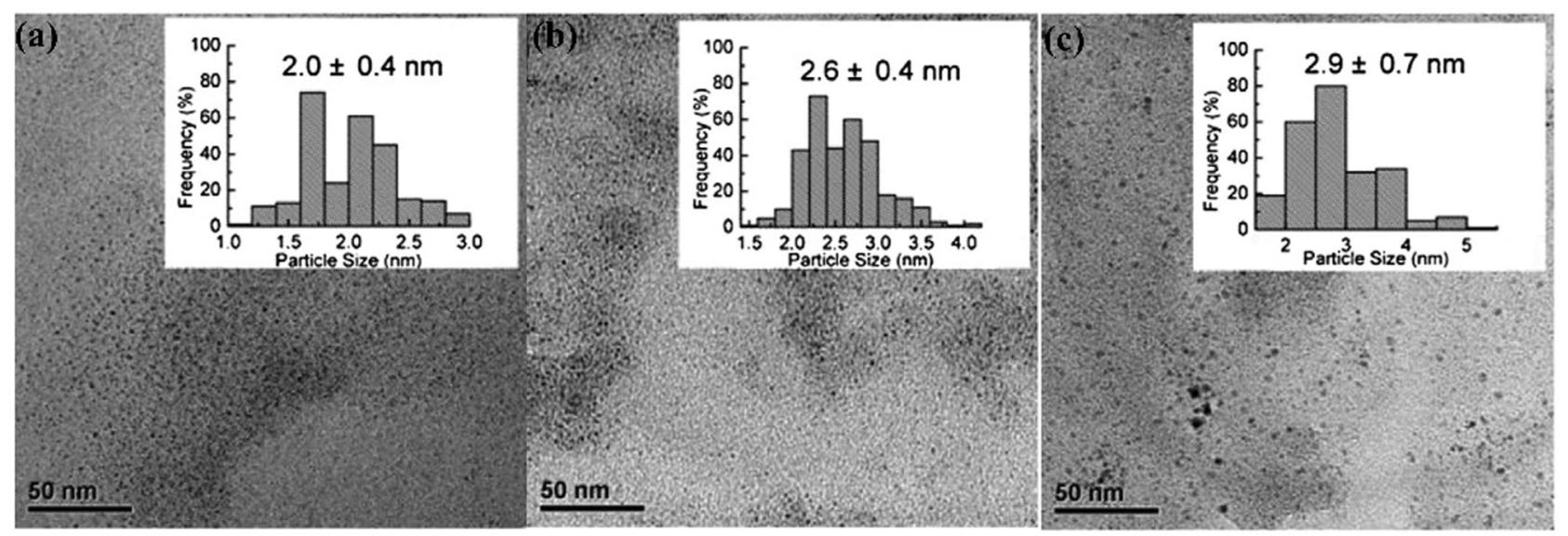

Figure 4: TEM images of the Pt NPs synthesized at (a) $30^{\circ} \mathrm{C}$, (b) $60^{\circ} \mathrm{C}$, and (c) $90^{\circ} \mathrm{C}$ when the Cacumen platycladi percentage and initial Pt( $(1)$ concentration were $50 \%$ and $1 \mathrm{mM}$, respectively (reprinted from ref. [12], copyright 2020, with permission from Elsevier).

affected and hence the donation of electrons by changing $\mathrm{pH})$. Simultaneously, the solution $\mathrm{pH}$ controls the activity of the functional groups in the plant extract/biomass, which in turn determines the reduction rate of the metal salt [131].

Al-Radadi [122] used solutions of diverse $\mathrm{pH}(1.5-8.5)$ to analyze the impact of $\mathrm{pH}$ on the rate of reaction and synthesis of Pt NPs. The synthesis of Pt NPs was reported to be faster in the basic medium compared to an acidic solution. Overall, the synthesis of Pt NPs increases as the $\mathrm{OH}$ concentration (alkalinity) of the dispersive medium increases. For acidic medium, bundles of Pt NPs are formed with particles of varied shapes and sizes. More specifically, at $\mathrm{pH} 1.5,3.5,5.5$, and 7.5 , the shapes and sizes of the synthesized Pt NPs are rod-shaped with a size of $700.5 \times 84.1 \mathrm{~nm}$, spherical with a size range of $5-5.4 \mathrm{~nm}$, spherical with a size of $2.3 \mathrm{~nm}$, and spherical with a size range of $5-13.8 \mathrm{~nm}$, respectively, as displayed by red data points with size variation bar in Figure 1.

Karim et al. [132] investigated the impact of $\mathrm{pH}$ on the synthesis of Pt NPs using orange peel extract. The Pt NPs synthesized at $\mathrm{pH} 3$ showed relatively less agglomeration and asymmetrical distribution of Pt NPs with a mean particle size distribution of $2.2 \mathrm{~nm}$. At $\mathrm{pH} 5$, the Pt NPs remain irregularly distributed with a high concentration of nanoparticles at specific spots, but a portion of spots showing particles with reduced sphericity and average particle size of $2.2 \mathrm{~nm}$. By increasing the $\mathrm{pH}$ to 9 , the $\mathrm{Pt}$ NPs become uniformly distributed, although there are still bare areas at the center. Here, the average particle size slightly decreases to $2 \mathrm{~nm}$. At pH 11, the NPs become more regularly distributed with further reduction in particle size to $1.8 \mathrm{~nm}$. At $\mathrm{pH} 13$, the Pt NPs remain spherically shaped, however, but begin to agglomerate to form larger $\mathrm{Pt}$ clusters, as displayed by black dashed line in Figure 1.
Nishanthi et al. [124] also assessed the $\mathrm{pH}$ effect on Pt NPs synthesized using the rind extract of Garcinia mangostana L. The optical spectra of Pt NPs synthesized under different $\mathrm{pH}$ values (4-8) are shown in Figure 2. A slight redshift $(\sim 6 \mathrm{~nm})$ is observed at acidic $\mathrm{pH}$, which is possibly due to the presence of larger nanoparticles, while the blue shift in the SPR $(\sim 4 \mathrm{~nm})$ at alkali $\mathrm{pH}$ can result from the formation of smaller nanoparticles.

\subsection{Reaction temperature}

Reaction temperature is an additional vital factor that controls the size, morphology, and synthesis rate of

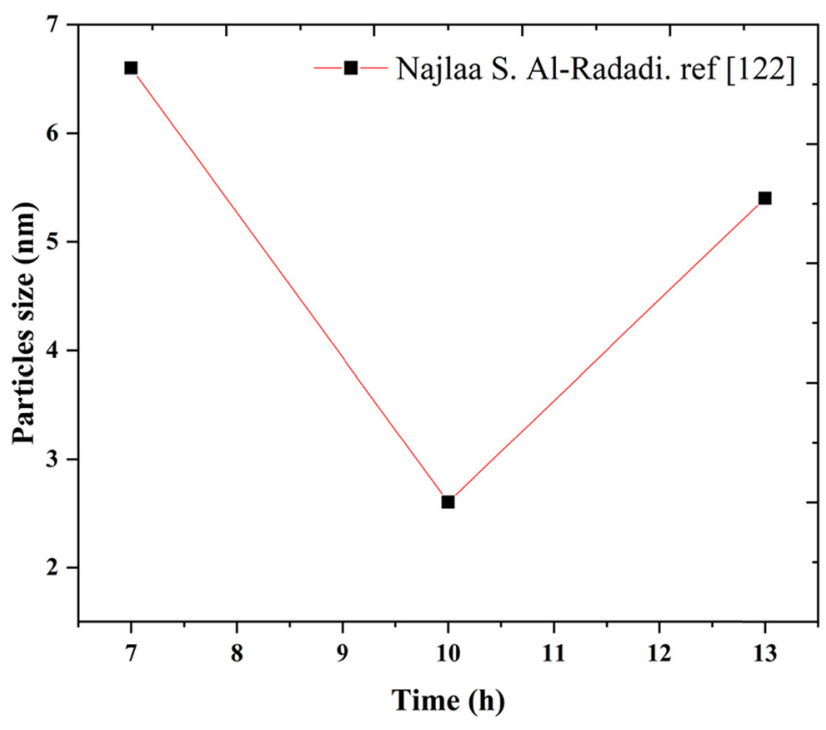

Figure 5: The effect of reaction time on the particle size variation of Pt NPs at room temperature, adapted from ref. [122]. 


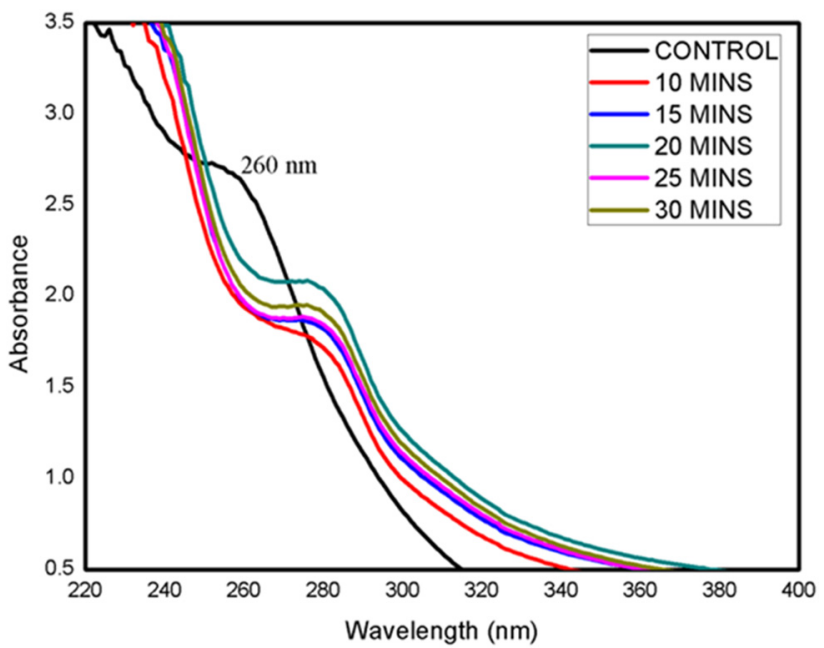

Figure 6: The optical spectra present the effect of the reaction time of green synthesis on the absorption spectra of Pt NPs (reprinted from ref. [124], copyright 2020, with permission from Elsevier).

Pt NPs. Similarly, the production of nucleation centers increases with increase in reaction temperature which then enhances the biosynthesis rate. Thirumurugan et al. [119] investigated the biosynthesis of Pt NPs from Azadirachta indica extract. Transmission electron microscopy (TEM) analysis shows the synthesis of polydispersed nanoparticles of small to large spheres $(5-50 \mathrm{~nm})$. The rate of Pt NPs synthesis was found to increase with the reaction temperature. In another study, Pt NPs sized 2-12 nm were biosynthesized using the leaf extract of Diospyros kaki at $95^{\circ} \mathrm{C}$ with $\mathrm{H}_{2} \mathrm{PtCl}_{6} \cdot 6 \mathrm{H}_{2} \mathrm{O}$ as the precursor solution [101]. The reduction process of $\mathrm{Pt}^{4+}$ to $\mathrm{Pt}^{0}$ nanoparticles was optimized at $95^{\circ} \mathrm{C}$. As shown in Figure 3 (red dashed line), the average particle size reduced from $12 \mathrm{~nm}$ at $25^{\circ} \mathrm{C}$ to $5 \mathrm{~nm}$ at $95^{\circ} \mathrm{C}$, which is attributable to the increasing rate of reduction. Al-Radadi [122] investigated the impact of reaction temperature on the biosynthesis of Pt NPs using Ajwa dates extract. TEM images reported the average particle sizes of the spherical Pt NPs are 3.4 and $2.6 \mathrm{~nm}$ at $20^{\circ} \mathrm{C}$ and $30^{\circ} \mathrm{C}$, respectively, as displayed by black dashed line in Figure 3. On the other hand, Zheng et al. [12] explored the effect of reaction temperature on the biosynthesis of Pt NPs using Cacumen platycladi extract (CPE). In this work, as shown in Figure 4, the TEM images of the Pt NPs reported particle sizes of $2.0 \pm 0.4,2.6 \pm 0.4$, and $2.9 \pm 0.7 \mathrm{~nm}$ at $30^{\circ} \mathrm{C}, 60^{\circ} \mathrm{C}$, and $90^{\circ} \mathrm{C}$, respectively. This indicates increase in the size of Pt NPs with reaction temperature, as depicted by dotted blue line in Figure 3. Under similar precursor concentration but higher synthesis reaction temperature, smaller particles with narrower size distribution are dominant, due to the fact that homogeneous nucleation is enhanced at a higher reaction temperature if the precursor undergoes complete reduction [133]. This is plausible as the $\mathrm{Pt}(\mathrm{II})$ conversion is directly linked to the accessibility of a $\mathrm{Pt}^{0}$ source. Thus, the rate of $\mathrm{Pt}(\mathrm{II})$ conversion was not high at either $30^{\circ} \mathrm{C}$ or $60^{\circ} \mathrm{C}$ owing to the deficient $\mathrm{Pt}^{0}$ source. In contrast, at higher reaction temperature $\left(90^{\circ} \mathrm{C}\right)$, the abundance of $\mathrm{Pt}^{0}$ source favors the growth of the Pt NPs. For this reason, the size of the Pt NPs was relatively larger as the reaction temperature increased. The reaction temperature of $90^{\circ} \mathrm{C}$ was thus implemented in successive tests to guarantee high conversion of $\mathrm{Pt}(\mathrm{II})$.

\subsection{Reaction time}

The duration of reaction/incubation of the suspension also significantly affects the size, morphology, and degree of nanoparticle synthesized using plant-based biomaterials. Al-Radadi [122] investigated the impact of reaction time on the properties of Pt NPs synthesized using Ajwa dates extract. Figure 5 showed changes in particle size of the synthesized Pt NPs $(6.6,2$, and $5.4 \mathrm{~nm})$ with increasing duration of reaction time $(7,10$, and $13 \mathrm{~h}$ ).

Similarly, Nishanthi et al. [124] reported that the most favorable reaction time for the biosynthesis of Pt NPs is $10 \mathrm{~min}$ after the addition of rind extract of Garcinia mangostana at ambient temperature. As observed in the spectra (Figure 6), nucleation growth increased with reaction time, although no significant spectral change is observed after $10 \mathrm{~min}$, which indicated completion of the synthesis within a short duration.

\subsection{Plant extract/biomass dosage}

The concentration of plant extract regularly determines the effectiveness of nanoparticle synthesis. Numerous studies reported that increasing the concentration of plant extract in biomass dosage improves the synthesis of nanoparticles in addition to modifying their morphology [12,134].

Zheng et al. [12] evaluated the differences in $\mathrm{Pt}(\mathrm{II})$ conversion over a period at varied dosages of CPE $(10 \%$, $30 \%, 50 \%$, and $70 \%)$. Pt(II) conversion was found to proportionally increase with CPE percentage and could surpass $95 \%$ following $25 \mathrm{~h}$ of bioreduction at CPE percentage of $70 \%$. In addition, TEM images showed the 

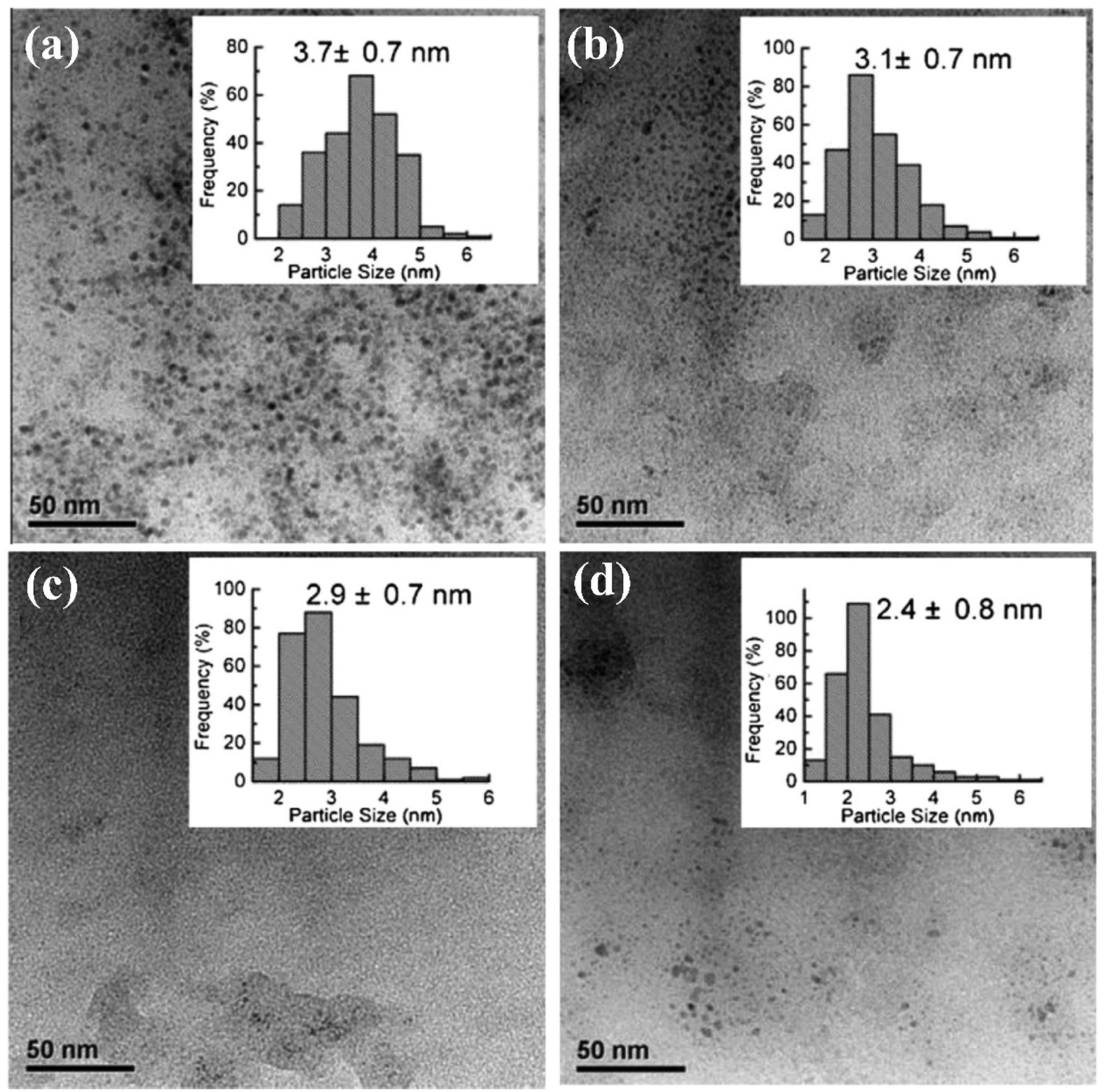

Figure 7: TEM images of the Pt NPs synthesized under different percentages of CPE: (a) $10 \%$, (b) $30 \%$, (c) $50 \%$, and (d) $70 \%$ for reaction temperature of $90^{\circ} \mathrm{C}$ and preliminary Pt(II) concentration of $0.5 \mathrm{mM}$ (reprinted from ref. [12], copyright 2020, with permission from Elsevier).

Pt NPs were spherically shaped and the histograms insets indicate (Figure 7) that the particle sizes of Pt NPs synthesized at different percentages of CPE (10\%, 30\%, $50 \%$, and $70 \%$ ) were $3.7 \pm 0.7,3.1 \pm 0.7,2.9 \pm 0.7$, and $2.4 \pm 0.8 \mathrm{~nm}$, respectively, as shown in Figure 7 .

Al-Radadi [122] researched the impact of variable concentration of Ajwa dates extract on the properties of synthesized Pt NPs. The NPs were prepared via the addition of different volumes of Ajwa dates extract (2, 3, 4, and $5 \mathrm{~mL}$ ) to $5 \mathrm{~mL}$ of $\mathrm{H}_{2} \mathrm{PtCl}_{6}$ stock solutions under incubation/ reaction time of $10 \mathrm{~h}$ at ambient temperature. Based on Figure 8, the particle sizes of the synthesized Pt NPs were 11.6, 7.3, 4.5, and $2.6 \mathrm{~nm}$ for 2, 3, 4, and $5 \mathrm{~mL}$ of Ajwa dates extract, respectively. Thus, it can be inferred that the particle size of Pt NPs decreases as the concentration of plant extract increases (Ajwa dates). 


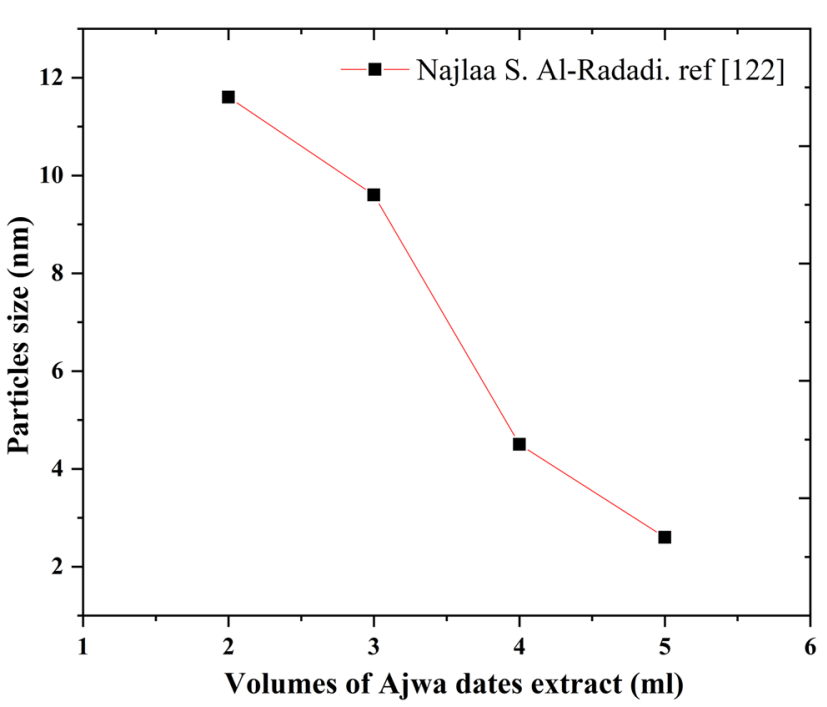

Figure 8: The effect of different concentration of Ajwa extract on the particle size variation of Pt NPs with $5 \mathrm{~mL}$ of $\mathrm{H}_{2} \mathrm{PtCl}_{6}$ stock solutions after $10 \mathrm{~h}$ at the ordinary temperature, adapted from ref. [122].

\section{Conclusion}

The effectiveness of conventional (physical and chemical) methods is constrained by a few critical limitations that include the use of harmful and costly chemicals, intricate preparation requirement, and high energy utilization. Hence, this work emphasizes on the use of green synthesis as an alternative approach for synthesizing Pt NPs from plants due to its simplicity, convenience, inexpensiveness, easy scalability, low energy requirement, environmental friendliness, and minimum use of hazardous substances and maximized the effectiveness of the synthesis process. The biosynthesis of NPs can provide more stability in terms of size and shape, as well as increase in the production yield. The bioreduction of metal nanoparticles is enabled by various bioactive molecules contained in plants. The plant extracts can also serve as capping or stabilizing agents during the synthesis process. Finally, this review affirms the effects of different critical parameters $(\mathrm{pH}$, reaction temperature, reaction time, and biomass dosage) on the size and shape of Pt NPs. For instance, the shape of Pt NPs can be altered with the change of $\mathrm{pH}$ value, and the average particle size of Pt NPs was reported to decrease with increasing $\mathrm{pH}$, reaction temperature, and concentration of plant extract.

Acknowledgments: We wish to thank Universiti Sains Malaysia for financial assistance in the form of FRGS Grant (203/PFIZIK/6711768) to support this work.

Conflicts of interest: There are no conflicts of interest.

\section{References}

[1] Nie Z, Petukhova A, Kumacheva E. Properties and emerging applications of self-assembled structures made from inorganic nanoparticles. Nat Nanotechnol. 2010;5:15.

[2] Pugazhendhi A, Edison TNJI, Karuppusamy I, Kathirvel B. Inorganic nanoparticles: a potential cancer therapy for human welfare. Int J Pharm. 2018;539:104-11.

[3] Chen A, Holt-Hindle P. Platinum-based nanostructured materials: synthesis, properties, and applications. Chem Rev. 2010;110:3767-804.

[4] Pedone D, Moglianetti M, De Luca E, Bardi G, Pompa PP. Platinum nanoparticles in nanobiomedicine. Chem Soc Rev. 2017;46:4951-75.

[5] Mafuné F, Kohno J-Y, Takeda Y, Kondow T. Dissociation and aggregation of gold nanoparticles under laser irradiation. J Phys Chem B. 2001;105:9050-6.

[6] Nakano S, Akedo J, Ogiso H. Platinum nanoparticle catalyst support technique by ion implantation and surface etching (IISE) method. Surf Coat Technol. 2007;201:8539-41.

[7] Van Rheenen P, McKelvy M, Glaunsinger W. Synthesis and characterization of small platinum particles formed by the chemical reduction of chloroplatinic acid. J Solid State Chem. 1987;67:151-69.

[8] Murphin Kumar PS, Thiripuranthagan S, Imai T, Kumar G, Pugazhendhi A, Vijayan SR, et al. Pt nanoparticles supported on mesoporous $\mathrm{CeO}_{2}$ nanostructures obtained through green approach for efficient catalytic performance toward ethanol electro-oxidation. ACS Sustainable Chem Eng. 2017;5:11290-9.

[9] Leong GJ, Schulze MC, Strand MB, Maloney D, Frisco SL, Dinh HN, et al. Shape-directed platinum nanoparticle synthesis: nanoscale design of novel catalysts. Appl Organomet Chem. 2014;28:1-17.

[10] Zhang X, Xia Z, Huang Y, Jia Y, Sun X, Li Y, et al. Shapecontrolled synthesis of Pt nanopeanuts. Sci Rep. 2016;6:31404.

[11] Duan H, Wang D, Li Y. Green chemistry for nanoparticle synthesis. Chem Soc Rev. 2015;44:5778-92.

[12] Zheng B, Kong T, Jing X, Odoom-Wubah T, Li X, Sun D, et al. Plant-mediated synthesis of platinum nanoparticles and its bioreductive mechanism. J Colloid Interface Sci. 2013;396:138-45.

[13] Kuppusamy P, Yusoff MM, Maniam GP, Govindan N. Biosynthesis of metallic nanoparticles using plant derivatives and their new avenues in pharmacological applications - an updated report. Saudi Pharm J. 2016;24:473-84.

[14] Liu Y, Li D, Sun S. Pt-Based composite nanoparticles for magnetic, catalytic, and biomedical applications. J Mater Chem. 2011;21:12579-87.

[15] Papst S, Brimble MA, Evans CW, Verdon DJ, Feisst V, Dunbar PR, et al. Cell-targeted platinum nanoparticles and nanoparticle clusters. Org Biomol Chem. 2015;13:6567-72.

[16] Zhang L, Roling LT, Wang X, Vara M, Chi M, Liu J, et al. Platinum-based nanocages with subnanometer-thick walls and well-defined, controllable facets. Science. 2015;349:412-6.

[17] Le Guével X, Trouillet V, Spies C, Jung G, Schneider M. Synthesis of yellow-emitting platinum nanoclusters by ligand etching. J Phys Chem C. 2012;116:6047-51. 
[18] Crist RM, Grossman JH, Patri AK, Stern ST, Dobrovolskaia MA, Adiseshaiah PP, et al. Common pitfalls in nanotechnology: lessons learned from NCl's nanotechnology characterization laboratory. Integr Biol. 2012;5:66-73.

[19] Bönnemann H, Richards RM. Nanoscopic metal particles synthetic methods and potential applications. Eur J Inorg Chem. 2001;2001;2455-80.

[20] Zhao W, Zhou X, Xue Z, Wu B, Liu X, Lu X. Electrodeposition of platinum nanoparticles on polypyrrole-functionalized graphene. J Mater Sci. 2013;48:2566-73.

[21] Raoof JB, Ojani R, Hosseini SR. Electrocatalytic oxidation of methanol onto platinum particles decorated nanostructured poly (1, 5-diaminonaphthalene) film. J Solid State Electrochem. 2012;16:2699-708.

[22] Mahmoud M, El-Sayed M. Metallic double shell hollow nanocages: the challenges of their synthetic techniques. Langmuir. 2012;28:4051-9.

[23] Mahmoud M, El-Sayed M. Time dependence and signs of the shift of the surface plasmon resonance frequency in nanocages elucidate the nanocatalysis mechanism in hollow nanoparticles. Nano Lett. 2011;11:946-53.

[24] Saminathan K, Kamavaram V, Veedu V, Kannan AM. Preparation and evaluation of electrodeposited platinum nanoparticles on in situ carbon nanotubes grown carbon paper for proton exchange membrane fuel cells. Int J Hydrogen Energy. 2009;34:3838-44.

[25] Shafiei M, Riahi A, Sen F, Alpas A. Improvement of platinum adhesion to carbon surfaces using PVD coatings. Surf Coat Technol. 2010;205:306-11.

[26] Tao AR, Habas S, Yang P. Shape control of colloidal metal nanocrystals. small. 2008;4:310-25.

[27] Chen J, Lim B, Lee EP, Xia Y. Shape-controlled synthesis of platinum nanocrystals for catalytic and electrocatalytic applications. Nano Today. 2009;4:81-95.

[28] Lim SI, Ojea-Jiménez I, Varon M, Casals E, Arbiol J, Puntes V. Synthesis of platinum cubes, polypods, cuboctahedrons, and raspberries assisted by cobalt nanocrystals. Nano Lett. 2010;10:964-73.

[29] Miyabayashi K, Nakamura S, Miyake M. Synthesis of small platinum cube with less than $3 \mathrm{~nm}$ by the control of growth kinetics. Cryst Growth Des. 2011;11:4292-5.

[30] Shahbazali E, Hessel V, Noël T, Wang Q. Metallic nanoparticles made in flow and their catalytic applications in organic synthesis. Nanotechnol Rev. 2014;3:65-86.

[31] Jurczakowski R, Lewera A, Kulboka P. Flow system method for preparing substantially pure nanoparticles, nanoparticles obtained by this method and use thereof, in, Google Patents, 2015.

[32] Kang Y, Ye X, Murray CB. Size-and shape-selective synthesis of metal nanocrystals and nanowires using $\mathrm{CO}$ as a reducing agent. Angew Chem Int Ed. 2010;49:6156-9.

[33] Zhou W, Wu J, Yang H. Highly uniform platinum icosahedra made by hot injection-assisted GRAILS method. Nano Lett. 2013;13:2870-4.

[34] Grace AN, Pandian K. One pot synthesis of polymer protected $\mathrm{Pt}, \mathrm{Pd}, \mathrm{Ag}$ and Ru nanoparticles and nanoprisms under reflux and microwave mode of heating in glycerol - a comparative study. Mater Chem Phys. 2007;104:191-8.

[35] Kou J, Bennett-Stamper C, Varma RS. Green synthesis of noble nanometals ( $\mathrm{Au}, \mathrm{Pt}, \mathrm{Pd})$ using glycerol under microwave irradiation conditions. ACS Sustainable Chem Eng. 2013;1:810-6.

[36] Zhao S-Y, Chen S-H, Wang S-Y, Li D-G, Ma H-Y. Preparation, phase transfer, and self-assembled monolayers of cubic Pt nanoparticles. Langmuir. 2002;18:3315-8.

[37] Yang J, Lee JY, Deivaraj T, Too H-P. An improved procedure for preparing smaller and nearly monodispersed thiol-stabilized platinum nanoparticles. Langmuir. 2003;19:10361-5.

[38] Yee C, Scotti M, Ulman A, White H, Rafailovich M, Sokolov J. One-phase synthesis of thiol-functionalized platinum nanoparticles. Langmuir. 1999;15:4314-6.

[39] Perez H, Pradeau J, Albouy P, Perez-Omil J. Synthesis and characterization of functionalized platinum nanoparticles. Chem Mater. 1999;11:3460-3.

[40] Eklund SE, Cliffel DE. Synthesis and catalytic properties of soluble platinum nanoparticles protected by a thiol monolayer. Langmuir. 2004;20:6012-8.

[41] Ghosh A, Stellacci F, Kumar R. New mixed ligand coated platinum nanoparticles for heterogeneous catalytic applications. Catal Today. 2012;198:77-84.

[42] Adil SF, Assal ME, Khan M, Al-Warthan A, Siddiqui MRH, Liz-Marzán LM. Biogenic synthesis of metallic nanoparticles and prospects toward green chemistry. Dalton Trans. 2015;44:9709-17.

[43] Moglianetti M, De Luca E, Pedone D, Marotta R, Catelani T, Sartori B, et al. Platinum nanozymes recover cellular ROS homeostasis in an oxidative stress-mediated disease model. Nanoscale. 2016;8:3739-52.

[44] Horie M, Kato H, Endoh S, Fujita K, Nishio K, Komaba LK, et al. Evaluation of cellular influences of platinum nanoparticles by stable medium dispersion. Metallomics. 2011;3:1244-52.

[45] Taurino I, Sanzó G, Mazzei F, Favero G, De Micheli G, Carrara S. Fast synthesis of platinum nanopetals and nanospheres for highly-sensitive non-enzymatic detection of glucose and selective sensing of ions. Sci Rep. 2015;5:15277.

[46] Yin T, Wang Z, Li X, Li Y, Bian K, Cao W, et al. Biologically inspired self-assembly of bacitracin-based platinum nanoparticles with anti-tumor effects. N J Chem. 2017;41:2941-8.

[47] Zhang L, Laug L, Munchgesang W, Pippel E, Gösele U, Brandsch M, et al. Reducing stress on cells with apoferritinencapsulated platinum nanoparticles. Nano Lett. 2009;10:219-23.

[48] Fan J, Yin J-J, Ning B, Wu X, Hu Y, Ferrari M, et al. Direct evidence for catalase and peroxidase activities of ferritin platinum nanoparticles. Biomaterials. 2011;32:1611-8.

[49] Liu X, Wei W, Wang C, Yue H, Ma D, Zhu C, et al. Apoferritincamouflaged Pt nanoparticles: surface effects on cellular uptake and cytotoxicity. J Mater Chem. 2011;21:7105-10.

[50] Wang X, Zhang Y, Li T, Tian W, Zhang Q, Cheng Y. Generation 9 polyamidoamine dendrimer encapsulated platinum nanoparticle mimics catalase size, shape, and catalytic activity. Langmuir. 2013;29:5262-70.

[51] Yamamoto K, Imaoka T, Chun W-J, Enoki O, Katoh H, Takenaga M, et al. Size-specific catalytic activity of platinum clusters enhances oxygen reduction reactions. Nat Chem. 2009;1:397.

[52] Cheng HJ, Wu TH, Chien CT, Tu HW, Cha TS, Lin SY. Corrosionactivated chemotherapeutic function of nanoparticulate platinum as a cisplatin resistance-overcoming prodrug with limited sutophagy induction. Small. 2016;12:6124-33. 
[53] Bommersbach P, Chaker M, Mohamedi M, Guay D. Physicochemical and electrochemical properties of platinum - tin nanoparticles synthesized by pulsed laser Ablation for ethanol oxidation. J Phys Chem C. 2008;112:14672-81.

[54] Rakshit R, Bose S, Sharma R, Budhani R, Vijaykumar T, Neena $S$, et al. Correlations between morphology, crystal structure, and magnetization of epitaxial cobalt-platinum films grown with pulsed laser ablation. J Appl Phys. 2008;103:023915.

[55] Paschos O, Choi P, Efstathiadis H, Haldar P. Synthesis of platinum nanoparticles by aerosol assisted deposition method. Thin Solid Films. 2008;516:3796-801.

[56] Ke X, Bittencourt C, Bals S, Van Tendeloo G. Low-dose patterning of platinum nanoclusters on carbon nanotubes by focused-electron-beam-induced deposition as studied by TEM. Beilstein J Nanotechnol. 2013;4:77-86.

[57] Büchel R, Strobel R, Krumeich F, Baiker A, Pratsinis SE. Influence of $\mathrm{Pt}$ location on $\mathrm{BaCO}_{3}$ or $\mathrm{Al}_{2} \mathrm{O}_{3}$ during $\mathrm{NO}_{x}$ storage reduction. J Catal. 2009;261:201-7.

[58] Choi ID, Lee H, Shim Y-B, Lee D. A one-step continuous synthesis of carbon-supported Pt catalysts using a flame for the preparation of the fuel electrode. Langmuir. 2010;26:11212-6.

[59] Dhand C, Dwivedi N, Loh XJ, Ying ANJ, Verma NK, Beuerman RW, et al. Methods and strategies for the synthesis of diverse nanoparticles and their applications: a comprehensive overview. RSC Adv. 2015;5:105003-37.

[60] Kshirsagar P, Sangaru SS, Malvindi MA, Martiradonna L, Cingolani R, Pompa PP. Synthesis of highly stable silver nanoparticles by photoreduction and their size fractionation by phase transfer method. Colloids Surf A. 2011;392:264-70.

[61] Scaramuzza S, Zerbetto M, Amendola V. Synthesis of gold nanoparticles in liquid environment by laser ablation with geometrically confined configurations: insights to improve size control and productivity. J Phys Chem C. 2016;120:9453-63.

[62] Sylvestre J-P, Poulin S, Kabashin AV, Sacher E, Meunier M, Luong JH. Surface chemistry of gold nanoparticles produced by laser ablation in aqueous media. J Phys Chem B. 2004;108:16864-9.

[63] Correard F, Maximova K, Esteve M-A, Villard C, Roy M, Al-Kattan A, et al. Gold nanoparticles prepared by laser ablation in aqueous biocompatible solutions: assessment of safety and biological identity for nanomedicine applications. Int J Nanomed. 2014;9:5415.

[64] Yanson Al, Rodriguez P, Garcia-Araez N, Mom RV, Tichelaar FD, Koper MT. Cathodic corrosion: a quick, clean, and versatile method for the synthesis of metallic nanoparticles. Angew Chem Int Ed. 2011;50:6346-50.

[65] Torres-Chavolla E, Ranasinghe RJ, Alocilja EC. Characterization and functionalization of biogenic gold nanoparticles for biosensing enhancement. IEEE Trans Nanotechnol. 2010;9:533-8.

[66] Shah M, Fawcett D, Sharma S, Tripathy S, Poinern G. Green synthesis of metallic nanoparticles via biological entities. Materials. 2015;8:7278-308.

[67] Abdullaeva Z. Characterization of nanoparticles after biological synthesis. Synthesis of nanoparticles and nanomaterials. Cham: Springer; 2017. p. 177-95.
[68] Yasmin S, Nouren S, Bhatti HN, Iqbal DN, Iftikhar S, Majeed J, et al. Green synthesis, characterization and photocatalytic applications of silver nanoparticles using Diospyros lotus. Green Process Synth. 2020;9:87-96.

[69] Rose GK, Soni R, Rishi P, Soni SK. Optimization of the biological synthesis of silver nanoparticles using Penicillium oxalicum GRS-1 and their antimicrobial effects against common food-borne pathogens. Green Proc Synth. 2019;8:144-56.

[70] Ismail M, Gul S, Khan M, Khan MA, Asiri AM, Khan SB. Medicago polymorpha-mediated antibacterial silver nanoparticles in the reduction of methyl orange. Green Proc Synth. 2019;8:118-27.

[71] Eskandari-Nojedehi M, Jafarizadeh-Malmiri H, RahbarShahrouzi J. Hydrothermal green synthesis of gold nanoparticles using mushroom (Agaricus bisporus) extract: physico-chemical characteristics and antifungal activity studies. Green Proc Synth. 2018;7:38-47.

[72] Owaid MN, Rabeea MA, Aziz AA, Jameel MS, Dheyab MA. Mushroom-assisted synthesis of triangle gold nanoparticles using the aqueous extract of fresh Lentinula edodes (shiitake), Omphalotaceae. Env Nanotechnol Monit Manage. 2019;12:100270.

[73] Rabeea MA, Owaid MN, Aziz AA, Jameel MS, Dheyab MA. Mycosynthesis of gold nanoparticles using the extract of Flammulina velutipes, physalacriaceae, and their efficacy for decolorization of methylene blue. J Environ Chem Eng. 2020;8:103841.

[74] Isaac R, Gobalakrishnan S, Rajan G, Wu R-J, Pamanji SR, Khagga $M$, et al. An overview of facile green biogenic synthetic routes and applications of platinum nanoparticles. Adv Sci Eng Med. 2013;5:763-70.

[75] Whiteley C, Govender Y, Riddin T, Rai M. Enzymatic synthesis of platinum nanoparticles: prokaryote and eukaryote systems. Metal nanoparticles in microbiology. Berlin, Heidelberg: Springer; 2011. p. 103-34.

[76] Siddiqi KS, Husen A. Green synthesis, characterization and uses of palladium/platinum nanoparticles. Nanoscale Res Lett. 2016;11:482.

[77] Jameel MS, Aziz AA, Dheyab MA. Comparative analysis of platinum nanoparticles synthesized using sonochemicalassisted and conventional green methods. Nano-Struct Nano-Objects. 2020;23:100484.

[78] Bennett J, Attard GA, Deplanche K, Casadesus M, Huxter SE, Macaskie L, et al. Improving selectivity in 2-butyne-1,4-diol hydrogenation using biogenic Pt catalysts. ACS Catal. 2012;2:504-11.

[79] Gaidhani SV, Yeshvekar RK, Shedbalkar UU, Bellare JH, Chopade BA. Bio-reduction of hexachloroplatinic acid to platinum nanoparticles employing Acinetobacter calcoaceticus. Process Biochem. 2014;49:2313-9.

[80] Baskaran B, Muthukumarasamy A, Chidambaram S, Sugumaran A, Ramachandran K, Manimuthu TR. Cytotoxic potentials of biologically fabricated platinum nanoparticles from Streptomyces sp. on MCF-7 breast cancer cells. IET Nanobiotechnol. 2016;11:241-6.

[81] Martins M, Mourato C, Sanches S, Noronha JP, Crespo MB, Pereira IA. Biogenic platinum and palladium nanoparticles as new catalysts for the removal of pharmaceutical compounds. Water Res. 2017;108:160-8. 
[82] Lengke MF, Fleet ME, Southam G. Synthesis of platinum nanoparticles by reaction of filamentous cyanobacteria with platinum (IV) - chloride complex. Langmuir. 2006;22:7318-23.

[83] Brayner R, Barberousse H, Hemadi M, Djedjat C, Yéprémian $\mathrm{C}$, Coradin $\mathrm{T}$, et al. Cyanobacteria as bioreactors for the synthesis of $\mathrm{Au}, \mathrm{Ag}, \mathrm{Pd}$, and Pt nanoparticles via an enzyme-mediated route. J Nanosci Nanotechnol. 2007;7:2696-708.

[84] Shiny P, Mukherjee A, Chandrasekaran N. Haemocompatibility assessment of synthesised platinum nanoparticles and its implication in biology. Bioprocess Biosyst Eng. 2014;37:991-7.

[85] Shiny P, Mukherjee A, Chandrasekaran N. DNA damage and mitochondria-mediated apoptosis of A549 lung carcinoma cells induced by biosynthesised silver and platinum nanoparticles. RSC Adv. 2016;6:27775-87.

[86] Riddin T, Gericke M, Whiteley C. Analysis of the inter-and extracellular formation of platinum nanoparticles by Fusarium oxysporum f. sp. lycopersici using response surface methodology. Nanotechnology. 2006;17:3482.

[87] Govender Y, Riddin T, Gericke M, Whiteley CG. Bioreduction of platinum salts into nanoparticles: a mechanistic perspective. Biotechnol Lett. 2009;31:95-100.

[88] Longoria EC, Velasquez SM, Nestor AV, Berumen EA, Borja MA. Production of platinum nanoparticles and nanoaggregates using Neurospora crassa. J Microbiol Biotechnol. 2012;22:1000-4.

[89] Ghosh S, Nitnavare R, Dewle A, Tomar GB, Chippalkatti R, More $P$, et al. Novel platinum - palladium bimetallic nanoparticles synthesized by Dioscorea bulbifera: anticancer and antioxidant activities. Int J Nanomed. 2015;10:7477.

[90] Yang C, Wang M, Zhou J, Chi Q. Bio-synthesis of peppermint leaf extract polyphenols capped nano-platinum and their in-vitro cytotoxicity towards colon cancer cell lines (HCT 116). Mater Sci Eng C. 2017;77:1012-6.

[91] Tahir K, Nazir S, Ahmad A, Li B, Khan AU, Khan ZUH, et al. Facile and green synthesis of phytochemicals capped platinum nanoparticles and in vitro their superior antibacterial activity. J Photochem Photobiol B. 2017;166:246-51.

[92] Leo AJ, Oluwafemi OS. Plant-mediated synthesis of platinum nanoparticles using water hyacinth as an efficient biomatrix source - an eco-friendly development. Mater Lett. 2017;196:141-4.

[93] Nadaroglu H, Gungor AA, Ince S, Babagil A. Green synthesis and characterisation of platinum nanoparticles using quail egg yolk. Spectrochim Acta, Part A. 2017;172:43-47.

[94] Rashamuse K, Whiteley C. Bioreduction of Pt(Iv) from aqueous solution using sulphate-reducing bacteria. Appl Microbiol Biotechnol. 2007;75:1429-35.

[95] Riddin T, Govender Y, Gericke M, Whiteley C. Two different hydrogenase enzymes from sulphate-reducing bacteria are responsible for the bioreductive mechanism of platinum into nanoparticles. Enzyme Microb Technol. 2009;45:267-73.

[96] Riddin T, Gericke M, Whiteley C. Biological synthesis of platinum nanoparticles: effect of initial metal concentration. Enzyme Microb Technol. 2010;46:501-5.

[97] Syed A, Ahmad A. Extracellular biosynthesis of platinum nanoparticles using the fungus Fusarium oxysporum. Colloids Surf B. 2012;97:27-31.
[98] Lin X, Wu M, Wu D, Kuga S, Endo T, Huang Y. Platinum nanoparticles using wood nanomaterials: eco-friendly synthesis, shape control and catalytic activity for p-nitrophenol reduction. Green Chem. 2011;13:283-7.

[99] Coccia F, Tonucci L, Bosco D, Bressan M, d’Alessandro N. One-pot synthesis of lignin-stabilised platinum and palladium nanoparticles and their catalytic behaviour in oxidation and reduction reactions. Green Chem. 2012;14:1073-8.

[100] Lee H-J, Lee G, Jang NR, Yun JH, Song JY, Kim BS. Biological synthesis of copper nanoparticles using plant extract. Nanotechnology. 2011;1:371-4.

[101] Song JY, Kwon E-Y, Kim BS. Biological synthesis of platinum nanoparticles using Diopyros kaki leaf extract. Bioproc Biosyst Eng. 2010;33:159.

[102] Soundarrajan C, Sankari A, Dhandapani P, Maruthamuthu S, Ravichandran S, Sozhan G, et al. Rapid biological synthesis of platinum nanoparticles using Ocimum sanctum for water electrolysis applications. Bioproc Biosyst Eng. 2012;35:827-33.

[103] Bali R, Siegele R, Harris AT. Biogenic Pt uptake and nanoparticle formation in Medicago sativa and Brassica juncea. J Nanopart Res. 2010;12:3087-95.

[104] Raut RW, Haroon ASM, Malghe YS, Nikam BT, Kashid SB. Rapid biosynthesis of platinum and palladium metal nanoparticles using root extract of Asparagus racemosus Linn. Adv Mater Lett. 2013;4:650-4.

[105] Auddy B, Ferreira M, Blasina F, Lafon L, Arredondo F, Dajas F, et al. Screening of antioxidant activity of three Indian medicinal plants, traditionally used for the management of neurodegenerative diseases. J Ethnopharmacol. 2003;84:131-8.

[106] Wang S, Meckling KA, Marcone MF, Kakuda Y, Tsao R. Can phytochemical antioxidant rich foods act as anti-cancer agents? Food Res Int. 2011;44:2545-54.

[107] Jain S, Dwivedi J, Jain PK, Satpathy S, Patra A. Medicinal plants for treatment of cancer: a brief review. Pharmacogn J. 2016;8:87-102.

[108] Leguizamo MAO. Role of plant species in bioremediation of heavy metals from polluted areas and wastewaters. Adv Mater Wastewater Treat. 2017;223-61.

[109] Mittal J, Batra A, Singh A, Sharma MM. Phytofabrication of nanoparticles through plant as nanofactories. Adv Nat Sci Nanosci Nanotechnol. 2014;5:043002.

[110] Mishra S, Keswani C, Abhilash P, Fraceto LF, Singh HB. Integrated approach of agri-nanotechnology: challenges and future trends. Front Plant Sci. 2017;8:471.

[111] Sheny D, Philip D, Mathew J. Synthesis of platinum nanoparticles using dried Anacardium occidentale leaf and its catalytic and thermal applications. Spectrochim Acta Part A. 2013;114:267-71.

[112] Porcel E, Liehn S, Remita H, Usami N, Kobayashi K, Furusawa Y, et al. Platinum nanoparticles: a promising material for future cancer therapy? Nanotechnology. 2010;21:085103.

[113] Kim E-Y, Ham S-K, Shigenaga MK, Han O. Bioactive dietary polyphenolic compounds reduce nonheme iron transport across human intestinal cell monolayers. J Nutr. 2008;138:1647-51.

[114] Nadagouda MN, Varma RS. Green synthesis of silver and palladium nanoparticles at room temperature using coffee and tea extract. Green Chem. 2008;10:859-62. 
[115] Jha B, Rao M, Chattopadhyay A, Bandyopadhyay A, Prasad K, Jha AK. Punica granatum fabricated platinum nanoparticles: a therapeutic pill for breast cancer. AIP Conference Proceedings. Melville, NY, USA: AIP Publishing LLC; 2018. p. 030087.

[116] Şahin B, Aygün A, Gündüz H, Şahin K, Demir E, Akocak S, et al. Cytotoxic effects of platinum nanoparticles obtained from pomegranate extract by the green synthesis method on the MCF-7 cell line. Colloids Surf B. 2018;163:119-24.

[117] Dobrucka R, Długaszewska J. Biosynthesis and antibacterial activity of $\mathrm{ZnO}$ nanoparticles using Trifolium pratense flower extract. Saudi J Biol Sci. 2016;23:517-23.

[118] Alshatwi AA, Athinarayanan J, Subbarayan PV. Green synthesis of platinum nanoparticles that induce cell death and G2/M-phase cell cycle arrest in human cervical cancer cells. J Mater Sci Mater Med. 2015;26:7.

[119] Thirumurugan A, Aswitha P, Kiruthika C, Nagarajan S, Christy AN. Green synthesis of platinum nanoparticles using Azadirachta indica - An eco-friendly approach. Mater Lett. 2016;170:175-8.

[120] Ullah S, Ahmad A, Wang A, Raza M, Jan AU, Tahir K, et al. Bio-fabrication of catalytic platinum nanoparticles and their in vitro efficacy against lungs cancer cells line (A549). J Photochem Photobiol B. 2017;173:368-75.

[121] Aygun A, Gülbagca F, Ozer LY, Ustaoglu B, Altunoglu YC, Baloglu MC, et al. Biogenic platinum nanoparticles using black cumin seed and their potential usage as antimicrobial and anticancer agent. J Pharm Biomed Anal. 2020;179:112961.

[122] Al-Radadi NS. Green synthesis of platinum nanoparticles using Saudi's Dates extract and their usage on the cancer cell treatment. Arab J Chem. 2019;12:330-49.

[123] Ganaie S, Abbasi T, Abbasi S. Biomimetic synthesis of platinum nanoparticles utilizing a terrestrial weed Antigonon leptopus. Part Sci Technol. 2018;36:681-8.

[124] Nishanthi R, Malathi S, Palani P. Green synthesis and characterization of bioinspired silver, gold and platinum nanoparticles and evaluation of their synergistic antibacterial activity after combining with different classes of antibiotics. Mater Sci Eng C. 2019;96:693-707.

[125] Bogireddy N, Pal U, Kumar M, Domínguez J, Gomez LM, Agarwal V. Green fabrication of 2D platinum superstructures and their high catalytic activity for mitigation of organic pollutants. Catal Today. 2019.

[126] Kora AJ, Rastogi L. Peroxidase activity of biogenic platinum nanoparticles: a colorimetric probe towards selective detection of mercuric ions in water samples. Sens Actuators B. $2018 ; 254: 690-700$.

[127] Chelli VR, Golder AK. One pot green synthesis of Pt, Co and Pt@Co core-shell nanoparticles using Sechium edule. J Chem Technol Biotechnol. 2019;94:911-8.

[128] Aygun A, Gülbagca F, Ozer LY, Ustaoglu B, Altunoglu YC, Baloglu MC, et al. Biogenic platinum nanoparticles using black cumin seed and their potential usage as antimicrobial and anticancer agent. J Pharm Biomed Anal. 2019;179:112961.

[129] Kumar PV, Kala SMJ, Prakash K. Green synthesis derived Pt-nanoparticles using Xanthium strumarium leaf extract and their biological studies. J Environ Chem Eng. 2019;7:103146.

[130] Armendariz V, Herrera I, Jose-yacaman M, Troiani H, Santiago P, Gardea-Torresdey JL. Size controlled gold nanoparticle formation by Avena sativa biomass: use of plants in nanobiotechnology. J Nanopart Res. 2004;6:377-82.

[131] Bali R, Harris AT. Biogenic synthesis of Au nanoparticles using vascular plants. Ind Eng Chem Res. 2010;49:12762-72.

[132] Karim N, Rubinsin N, Burukan M, Kamarudin S. Sustainable route of synthesis platinum nanoparticles using orange peel extract. Int J Green Energy. 2019;16:1518-26.

[133] Zhou Y, Lin W, Huang J, Wang W, Gao Y, Lin L, et al. Biosynthesis of gold nanoparticles by foliar broths: roles of biocompounds and other attributes of the extracts. Nanoscale Res Lett. 2010;5:1351.

[134] Balamurugan M, Kandasamy N, Saravanan S, Ohtani N. Synthesis of uniform and high-density silver nanoparticles by using Peltophorum pterocarpum plant extract. Jpn J Appl Phys. 2014;53:05FB19. 